
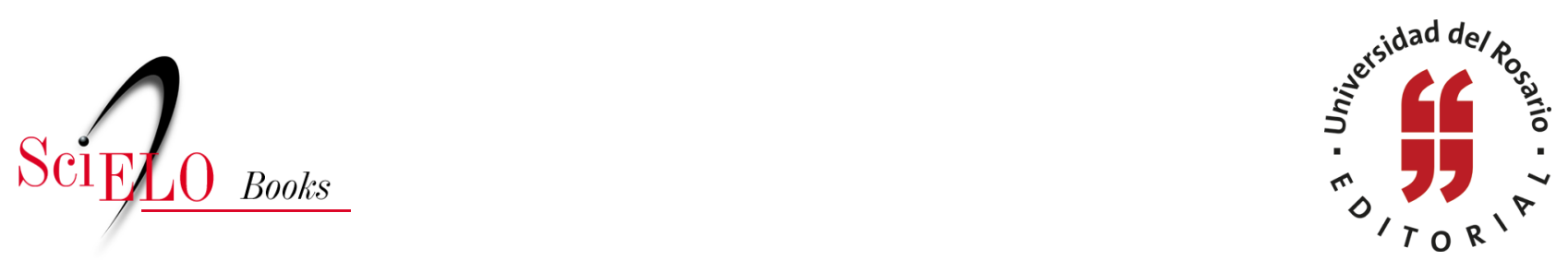

\title{
24. Mujeres en exceso
}

\author{
César Augusto Tapias Hernández
}

TAPIAS HERNÁNDEZ, C.A. Mujeres en exceso. In: Historias de familia: Etnografía delirante sobre el amor, la violencia y las drogas [online]. Bogotá: Editorial Universidad del Rosario, 2014, pp. 101-107. Textos de ciencias humanas collection. ISBN: 978-958-738-543-4. https://doi.org/10.7476/9789587385434.0025.

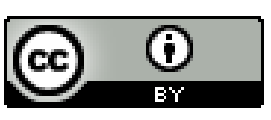

All the contents of this work, except where otherwise noted, is licensed under a Creative Commons Attribution 4.0 International license.

Todo o conteúdo deste trabalho, exceto quando houver ressalva, é publicado sob a licença Creative Commons Atribição 4.0.

Todo el contenido de esta obra, excepto donde se indique lo contrario, está bajo licencia de la licencia Creative Commons Reconocimento 4.0. 


\section{Mujeres en exceso}

¿Qué tontería cartesiana es pensar que los cantos de las aves son apenas unos gritos previamente programados que lanzan para indicar su presencia al sexo opuesto y cosas por el estilo! Cada canto de ave es una sincera liberación del yo al aire, que apenas podemos comprender. ;Yo!, dice cada grito, ;Yo, qué milagro! J. M. Coetzee, Diario de un mal año

De nuevo en casa de la tía Irene, sentados al comedor y afortunadamente lejos de la televisión. Aquíla televisión, como quizás en muchos otros muchos hogares, ocupa un lugar de privilegio, pues toda la familia le presta la atención que a lo mejor se niegan entre ellos. Aunque casos se dan en los cuales ni el más excitante avance de la modernidad rompe el diálogo intrafamiliar, y la familia sigue desempeñando su papel moldeante del individuo... sin massivas interferencias. Donde mi tía Irene, por lo menos, la tele está en la sala, y con eso se evitan que las palabras sean ahuyentadas de las alcobas cuando cada uno va a dormir.

En la sala se ocupan todos los muebles mirando la tele, y entre los comerciales de la novela Gotita de amor o las noticias de las siete de la noche, se hablan unos y se saludan los otros. Sobre la palabrería que se desata en la sala ancha de la tía Irene, y ante los ojos pintados de los abuelos en un par de cuadros que cuelgan en la pared, nos tomamos un tinto fumando de paso un Mustang. Las tiendas de por donde la tía deben surtirse de Mustang no más que para venderle cigarrillos Mustang a mi tía. Es raro ver a alguien fumando esa marca; ni mis primas, sus hijas, que como ella fuman... Ahora recuerdo que, de niño, le encendí un par de cigarros a mi tía... En la estufa: acercaba la cara al calor del fogón con ese pitillo en la boca, y aspiraba...

Beatriz llega del trabajo y su sobrina Sandra le sale al encuentro y le cuenta algo al oído. Se cuchichean en la habitación de mi tía entre sonrisas, jseguro que se trata de amores tanta risa! Luego las veré con la vecina Cristina, yendo hasta el teléfono 
público... Parecen novias cansonas. Y es que hace apenas un rato que la tía Irene ha debido regañar a Sandra por tardarse tanto en el teléfono. Ya venía don Arturo hablando, quejándose bajito:

-Esa muchacha no entiende, las visitas no se hacen por teléfono.

Pero como aquí lo que hay es un matriarcado, cuando habla Irene es cuando habla... la autoridad. Solo entonces se obedece. Dice la tía que es que eso nunca lo pierde un padre ante sus hijos: LA AUTORIDAD.

- Siempre él y ella merecerán el respeto de sus hijos. Luego de traerlos al mundo y haberlos levantado, es eso lo menos que puede pedirse...

Que los hijos necesitan amor, compañía; pero también templanza, dureza, criterio, exigencia, va contando Irene mientras se fuma otro cigarrillo. Sentada parece una reina la tía Irene, sosteniendo alto ese cigarrillo, aprobando y desaprobando las palabras de sus hijas sentadas ya a la mesa para comer... Un aire señorial se manda Irene hasta para hablar: manotea con la mano libre mientras habla, la otra de cuando en vez le acerca el cigarro a la boca justo en el espacio que le dejan las palabras... Y así se va confesando sobre el amor y cómo darlo. Cuando a ella le ha tocado ser dura ante los suyos, lo ha hecho. Y no deja de estar segura y convencida de lo que piensa, ejercer la autoridad sobre los hijos... Y no descarta volver a hacerlo si de nuevo siente que hace falta. Y eso que los hijos de la tía Irene ya marcan con el tres, treinta y punta... salvo Sandra, que en realidad es su nieta y no su hija... Aunque Sandra siempre le dirá mamá a mi tía Irene... Sandra apenas tiene diecisiete años; pero aun así, dice Irene, que hasta que pueda levantar la mano, la levanta si se siente irrespetada, desautorizada.

—A Sandra jamás se le mintió sobre Adriana, su verdadera mamá — dice la tía, cuando hemos logrado entrar en la conversa-. Siempre se le inculcó el llamarla mamá; pero es que Adriana era muy... ¡Adriana María nunca quiso a Sandra! Esa es la verdad... y yo me la aguanté mientras mi papá estuvo vivo. Él veía por los ojos de Adriana... Le daba pesar los castigos que yo le imponía, y no comía, intranquilo, pensándola cuando ella se desaparecía: “dónde estará esa muchacha, pasando hambre quizás y uno comiendo...”, decía el abuelo Gabriel.

-Yo me tuve que salir del trabajo por cuidar a Sandra. Adriana solo le pegaba y la castigaba. Ella era solo la mamá para jugar; mientras no tuviera que prepararle un tetero o ir a bañarla, no había problema...

Si bien en esta casa se fraguó la idea de armar un álbum familiar, aquello ocurrió oyendo lo que casualmente se decía, lo que deambulaba por el aire; pero hoy buscaba algo muy puntual: saber de Adriana y Nolberto, dos de los hijos de 
Irene, y a través de ellos, de los demás hijos suyos de toda esta casa amplia y cálida por dentro habitada por mujeres en exceso: Irene, Beatriz, Lucía, Sandra, Luisa... Pronto otra nieta, ¡seguro!

Hasta hace algunos días también Gloria y su hija. Los demás, Arturo y Gustavo (quien se ha alojado por unos días donde mi tía). De pronto pasan Nolberto y Luis, los hijos del primer matrimonio de Gloria... (No hay nieto que no busque la bendición de su abuela). Recuerdo a la Gloria tan enojada tan enojada que no hablaba cuando se devolvió para Bogotá. Gloria es una mujer negra como su papá Arturo, y tan guerrera como mi tía Irene: - Solo que un poco altanera - resalta Irene.

Ella, como Adriana, y quizás como Sandra, no se la deja montar de nadie, ni del marido ni de las cuñadas... Solo la tía Irene puede más, y como con ella nadie se mete, a la que no le gusten sus cosas, sus comentarios, o sus ideas, mejor se va. $Y$ así le pasó la última vez a la Gloria.

- Su altanería, su grosería no cuadraban en la casa.

Pero si de altanería se trata... a Arturo le parece una ofensa el que una hija tenga un hijo siendo soltera:

-Eso es como no valorar los sacrificios de los papás - dice.

Beatriz, por ejemplo, no piensa igual... Y esa controversia finalmente no genera problema alguno en esta casa. Solo un intercambio de palabras... dice mi prima:

- Papá, yo con usted no estoy de acuerdo...

Y Arturo la mira, pero ni él ni Beatriz dicen más...

Beatriz mira de nuevo la tele mientras va haciendo un lindo carrizo con sus piernas gruesas - morenas y aventuradas - . Las cruza suave, como en cámara lenta, jala hacia abajo y con certeza la falda corta que lleva, no dejando escapar nada... ni mis suspiros.

De pronto me descubro: obviando su opinión, embelesado viendo solo sus piernas... Discutíamos sobre lo especial que puede ser una casa llena de mujeres, aun cuando para esas mujeres el asunto no tenga nada de especial... Entonces, recato mi postura y empiezo a analizar... viendo a Arturo... a través suyo, veo a mi abuelo Gabriel. El viejo se la montó a mi tía Carmen, porque tampoco estaba casada con don José... Arturo era sobrino de mi abuelo Gabriel... Humm... los Fernández... (Y yo, que soy hijo de mi papá... Humm).

Amanda rompe el silencio diciendo que tampoco está de acuerdo... Beatriz, Amanda y también Adriana tuvieron hijas sin casarse (¿Qué significa todo esto?) — ¿Con qué no estás de acuerdo? - pregunto-. ¿Con lo que dice Arturo? -recalco. 
— ¡No!, con que pueda ser especial una casa llena de mujeres...

— iAaaahhhh, yaaa! Me lamento...

-Eso de muchas mujeres en la casa les permite a unas recostarse, echarse, dejarse ir, todas conchudas sin hacer nada más que dejándose atender...

Y se reserva nombres a la hora de quejarse. Amanda es una mujer delgada muy alta y más veloz que una gacela... de más joven era atleta, corría y jugaba basquetbol... La recuerdo corriendo detrás de mí, y eso que yo iba en la bici, volaooo... Y Amanda me alcanzaba.

Mi tía está mirando a sus hijas y las repara... como exponiéndomelas... y se alegra por Beatriz, que siempre encuentra trabajo; y se entristece por Amanda...

—Desde que perdió a Carlos Mario... Ay, qué pesar de mi hija...

Carlos Mario fue su último novio: un hombre radiante, contento... Un caballero fugado de la vida. Siento que no fue un juicio ni un reclamo la comparación de mi tía sobre el destino de mis primas... Según dice, hay encuentros que truncan la vida misma del que sea... Ahora mismo recuerdo a Carlos Mario con mi prima de la mano, su inquietud por mis historias y sus ganas de contar las suyas; pero la vida se le acaba a uno y uno todo sano, se queda no más con las ganas... Así como yo me quedé con las ganas de conocer más al primo Nolberto, quien en un cruce extraño de dos extraños también resultó fugado de esta vida.

—Estaría calvo, es casi seguro... - juró el tío Gustavo, un hermano de Arturo muy de la familia.

Él supo antes que nadie, y desde Titiribí, que aquí en Medellín había sido muerto un sobrino suyo, en un fin de semana, cuando la tía estaba en Bogotá.

- Para Nolberto la casa no existía de viernes a domingo; en esos días se perdía buscando adónde ir a parrandear... - dice Irene.

—Y ese último sábado jugó la Selección Colombia — recuerda Lucía- y como perdió... la decepción nos dio por silenciar la radio y la misma televisión...

Entonces de Titiribí llamaron a decir que en la radio hablaban de un muchacho asesinado a quien nadie iba a reclamar. Se llamaba Nolberto de Jesús Fernández Fernández, como el de Irene... y resultó ser el Nolberto de la tía Irene. Fue la misma Adriana quien lo pudo comprobar. Cuando supo la noticia, fue a la morgue y allá lo reconoció... Y que Nolberto (como lo es Beatriz) era la tranquilidad en pasta: el sello de la familia, dice y dice Gustavo: "así somos todos los Fernández: frescos, tranquilos".

De Adriana no se sabe nada desde que cuando Sandra hizo la primera comunión, y a pesar de su rebeldía y su grosería, la tía guardaba las esperanzas de volver 
a verla en los quince años de Sandra; pero Adriana María nunca apareció. Lo hará dentro de muchos años, con una nueva familia, verán...

Otro ausente de esta casa es el Darío. También resultó evadido por las calenturas que se respiran en los barrios altos de esta ciudad. Hoy también está en Bogotá... Pero al que nunca vi en esta casa fue a Carlos Arturo. Cuentan que de pelao él siempre prefirió el campo a estudiar. Iba todos los días a la escuela, pero jamás participaba de las clases y jamás a nadie le ocultó que no quería estudiar. Así, para evitar las mañas que enseña la ciudad, Carlos Arturo fue enviado a Titiribí, a trabajar...

Yo me explico ante la particularidad y lo especial que podría ser esta casa llena de mujeres. La mía, por ejemplo, llena de hombres, nos ha permitido a mi hermano y a mí jamás embalarnos ante los quehaceres, tan común y tradicionalmente asignados a las mujeres... Sin embargo, mi inquietud va más allá de los comportamientos más notorios. Sandra y Luisa pelean mucho, Sandra y Beatriz se la llevan bien, Lucía podría ser la más juiciosa y quizás sea Beatriz la que se recueste un poco... A Irene le parece inaudito que con tantas mujeres en una casa no se atienda debidamente a los hombres, aunque nunca ha permitido que hombre alguno se la monte a alguna de sus hijas solo porque le sirva la comida. El Darío alguna vez lo intentó...

- iY, seguro, no pudo...!

Arturo pasa la mayor parte del tiempo viéndome preguntar y descartar información; incluso podría decirse que ni siquiera le interesaba lo que se hablaba. Con cierta distancia me pedía mejor que viera en la tele al presidente Pastrana argumentando por qué Colombia merece hacer la Copa América:

-Vea, mire... por qué mejor no va y le hace un reportaje al presidente... Para qué quiere saber tanto...

Arturo es un hombre alto, grueso y moreno. De joven, sin duda, fue muy pintoso y el porte que seguro tuvo puede verse en sus fotografías. Arturo e Irene son primos, y según cuentan eso nunca significó líos, aunque eso de amor entre primos tampoco fuera la cosa más común. Irene sí tuvo miedo los primeros días, pero a la final ningún hijo bobo, ni con cola de marrano.

- Lo de Yiyo fue escopolamina, y lo de Byron, el hijo del tío Gabriel, de leer tanto lo Biblia. Esos son los únicos locos entre nosotros...

Eso lo dice Arturo y lo apoya Lucía, aun cuando Irene establece otra teoría:

-Byron estudió mucho, siempre fue muy inteligente y se preparó; pero él no encontraba trabajo, donde poner su talento... Lo lanzó a la pensadera y eso lo volvió medio loco. 
Así, pues, no parece tan difícil establecer patrones que no se repitan en la familia, además de la tranquilidad de Nolberto y la de Beatriz, y la de cualquier ser humano... Uno no siempre esta agitado... Me parece clave ver que Irene castigaba a Adriana y eso a papito Gabriel le molestaba... y Adriana de mamá adolescente también castigaba a su bebé... Ahí está la vuelta de Van Gogh, apropósito de repeticiones, o espirales como lo propuse en Fumando mañas (Tapias, 2010):

—Los Fernández siempre hemos sido eso, frescos —insiste Gustavo.

— ¿Y quién lo va a contradecir? Solo quisiera notar que en una casa con mujeres en exceso como esta, hay que ver es cómo se transfiere el conocimiento del conocimiento que ofrecen... La vida, la experiencia y la familia, es decir, de nuevo... La existencia... La tarde pasando (se parece a la de ayer...), pasando ante la mirada serena de mi tía... La tarde anocheciendo y el cigarrillo cada vez más fumado... acabado como los otros cigarros fumados... La puerta abierta, la tele prendida... la vida pasando en la casa de mi tía Irene.

$\infty \infty \infty$

Para doña Virginia Gutiérrez de Pineda (1998), los estudios de familia en Colombia se han movido entre varias tendencias temáticas no excluyentes: por una parte, están los estudios de composición y tipo de familia; por otra, podemos ver la crisis asociada al concepto de descomposición social. Por último, una línea de desarrollo más reciente, considerada resultado de la interrelación entre las esferas pública y privada, donde se reconoce el papel clave de la socialización y supervivencia material y afectiva del grupo familiar, y los requerimientos que para dicho desarrollo tienen en relación con la oferta de servicios sociales. Vemos, una vez más, que en el abordaje de la familia convergen múltiples factores que inciden positiva y negativamente en su análisis, por cuanto esta no es solo un hecho social, sino una experiencia de vida, lo que dificulta la separación entre posturas valorativas y analíticas.

Este delirio socioantropológico quiere plegarse a la tendencia "crisis de familia" pero asociada al concepto de transformación, que también defiende la profesora Virginia aludiendo a crisis en medio de transformaciones muy violentas que podemos leer etnográficamente; por ejemplo, el asesinato de miembros de la familia o el enojo de los padres ante el madresolterismo de sus hijas. Esto nos obliga a considerar dos aspectos centrales:

En primer lugar, la crisis social y política que surge con la migración del campo a la ciudad, movimientos humanos en muchas ocasiones derivados de la violencia 
política y que se involucran en otras formas de violencia una vez llegan a nuevos espacios en la ciudad: asaltos... intimidación... y la propia violencia intrafamiliar. Y, en segundo lugar, la crisis en función del lugar que ocupan las mujeres. Información del Departamento Administrativo Nacional de Estadística (DANE, 1998), obtenida de encuestas a hogares en 1978, y el Censo Nacional de Población de 1993, dejan ver que el predominio de la familia nuclear, como forma en la que se organiza más de la mitad de los hogares en Colombia, disminuye a expensas de leves incrementos en los arreglos unipersonales y las modalidades extendidas. Es el caso de familias con nietos y bisnietos, o de mujeres madres solteras que se quedan o regresan a casa de sus padres.

La profesora Virginia desagrega esa información y encuentra cambios sustanciales, como la disminución de la familia nuclear completa (padre, madre e hijos); en tanto aumentan hogares con un solo progenitor, por lo que habría que incluir a padres abandonadores. Ahí podría observarse la crisis en torno a la función de la mujer, en cuanto vanguardia de la transformación de la función económica, con el hombre que se rezaga o se dualiza ante el sexo. Pese a todas las contradicciones y modalidades de cambio, la función sexual gratificante pierde su restricción prematrimonial en la mujer, que ha entrado a obtenerla desde edades tempranas. 